\title{
High performance ceramic stones on the basis of by-products of waste heaps - screenings and coal slurry
}

\author{
Khungianos Yavruyan ${ }^{1}$, Vladimir Kotlyar ${ }^{1}$, Evgeniy Gaishun ${ }^{1 *}$, Anastasia Okhotnaya ${ }^{1}$, \\ Elizaveta Lotoshnikova ${ }^{1}$, Kristina Chanturiya ${ }^{1}$ \\ ${ }^{1}$ Don State Technical University, 344002, 1, pl. Gagarina, Rostov-on-Don, Russia
}

\begin{abstract}
General description of coal dumps products processing is described: medium factional materials - screenings that do not contain carbon; kiln fractional - coal sand, coal containing up to $30 \%$; petty factional - coal slurries, coal containing up to $50 \%$ are given. Ceramic kilns and technological properties of processing coal dumps products are given. Compositions of raw mixtures for obtaining products with a compressive strength of 10-15 $\mathrm{MPa}$ and density less than $800 \mathrm{~kg} / \mathrm{m} 3$, and considering the fact that the molding process is carried out semi-rigid extrusion and the necessity of minimum costs for firing is defined. Depending on the technological properties of screenings, depending on the degree of grinding and firing temperature is taken into account. Flow production of modern equipment is pointed out. Technical and economic indicators showing high profitability and the prospect of large-scale production of clay tiles on the basis of coal dumps processing products due to minimal manufacturing cost are mentioned. The carried out results of the work allowed to choose the raw materials and to develop the technological scheme of production of high-performance ceramic stones with a minimum cost. Implementation of the results in practice will create a highly profitable production and make the Rostov region a major manufacturer of ceramic wall.
\end{abstract}

\section{Introduction}

Large size high-performance ceramic stones are becoming more popular in modern construction. In Europe, it firmly occupies their niche and their share in housing construction reaches $70-90 \%$ of the total wall products $[1,2]$. This is due to the advantage of ceramic stones on a number of properties compared to other wall products. In Russia, this figure is still lower [3, 4]. One reason for this is the higher cost (on average 10-20\%)

\footnotetext{
"Corresponding author: subaru156@ya.ru
} 
compared with the blocks of gas silicate, though the last are inferior to ceramic stones on a number of physic-technical properties. Reducing the cost of clay tiles is possible if to reduce the cost of shipping products to customers. The cost price of products depends on many factors. The production plan is the cost of raw materials, productivity of the enterprise, technology costs, primarily fuel and energy costs, labor input per unit of output production and other factors. The cost of shipping can be reduced due to the distance to the consumer and logistics solutions.

Taking everything into attention, we have carried out a study on the establishment of the large-scale production possibility of high-performance ceramic stones on the rigid extrusion technology based products processing coal dumps of Eastern Donbass. Firstly, the cost of raw materials is almost zero, and in this case they contain carbon, which is regarded as complex fuel and polarizing component. Companies often have to bear the costs for the storage of by-products of coal dumps. Secondly, the Rostov region, which includes the Eastern Donbass, has its factories for the production of clay tiles, in spite of the high demand, and at a very favorable crossroads of transport routes. The implementation of our results and developments could make the Rostov region a major manufacturer of ceramic stones for their own security. According to preliminary calculations, in the short term, demand for large-size ceramic stones will be $200 \mathrm{mln}$ pieces in terms of standard bricks.

\section{Methods and materials}

The main aim of processing coal dumps at the moment is the extraction of coal anthracite. The fact that the content data in the man-made formations on average from $10 \%$ to $20 \%$. Volumes of dumps only in the Rostov region are hundreds of million tons.

In the process of extracting coal mine dumps passing several kinds of material, which are classified by petrographic and mineralogical grain structure as well as the number of the coal component $[5,6]$. Grits size elements from 5-6 $\mathrm{mm}$ to $150 \mathrm{~mm}$ show sandstones and siltstone, contain carbon, they are used as fillers in the construction and are of no interest for the production of clay tiles. Medium-grained material with a grain size from 2 to 5-6 $\mathrm{mm}$ (the screenings) represented siltstone and mudstone, also substantially free of carbon and can become the primary raw material for the production of clay tiles. Medium-grained material with a grain size from 2 to $5-6 \mathrm{~mm}$ (the screenings) represented siltstone and mudstone, also substantially free of carbon and can become the primary raw material for the production of clay tiles. Small fraction materials (coal sand cake) with a primary grain size of 0.5 to $2.5 \mathrm{~mm}$, as represented siltstone and mudstone may contain carbon in an amount up to $35 \%$. However, they do not have the necessary plastic properties and their use for the production of large-sized ceramic stones on the rigid extrusion technology is not quite appropriate. They are primarily used as a low-calorie fuel. Thin fractional materials with grain size less than $0.5 \mathrm{~mm}$, when the content of the fraction less than $0.16 \mathrm{~mm}$, usually call coal slurries, muds, coal dust. Coal content of averages is about $35 \%$. Application of modern technologies allows you to adjust the content of coal. Mineral component in them is represented with thin fractional mudstone, so they have plastic properties. The average ductility is about 7-10 units. Conducted contact feasibility study has shown that the most advantageous is to use the main raw material - screenings, and as an additional material - coal sludge, acting as the fuel and the pore-forming additives as well as additives improving molding properties [7, 8].

The article used the standard methods of ceramic raw materials research, specified in GOST 21216-2014 Raw clay. Test methods and also, given the nature stonelike main raw material, copyrights technique which takes into account the direct technological properties substantial dependence on the degree of crushing raw stone prominent [9-12]. 


\section{Results and discussion}

Studies have shown screenings processing waste heaps that are mainly represented by siltstones and mudstones. It is natural, as in the processing of waste heaps rock mass less durable breed pass into fines. In some cases, may be presented argillite like clay. The ratios of these components may vary, depending on the composition of the initial mining spoil [13-16]. The chemical composition of screenings (Table 1) has no basic differences from raw clay. Characteristic is clear predominance over sodium oxide, potassium oxide, due to the presence of micas and hydromicas and the high content of iron oxide.

Table 1. Averaged chemical composition of coal processing of dropout dumps in eastern donbass, $\%$ by weight.

\begin{tabular}{|c|c|c|c|c|c|c|c|c|}
\hline $\mathbf{P P P}$ & $\mathrm{SiO}_{2}$ & $\mathbf{A I}_{2} \mathbf{O}_{3}$ & $\mathbf{F e}_{2} \mathbf{O}_{3}$ & $\mathbf{C a O}$ & $\mathbf{M g O}$ & $\mathbf{S O}_{3}$ & $\mathbf{K}_{\mathbf{2}} \mathbf{O}$ & $\mathbf{N a}_{2} \mathbf{O}$ \\
\hline $9-11$ & $50-58$ & $16-22$ & $4-7$ & $1-4$ & $1-4$ & $0,2-0,7$ & $4-6$ & $0,2-1,0$ \\
\hline
\end{tabular}

Besides micas and hydromicas typical screenings minerals are feldspar (orthoclase, albite, anorthite) exposed to strong secondary changes, chlorite, kaolinite, quartz, ferruginous minerals. The figure 1 shows the typical X-ray screenings from waste heaps processing of one of the enterprises of the Eastern Donbass. Hydromica (illite) and mica diagnosed by diffraction peaks 4,48, 5,06 and 10,16 $\AA$. Feldspar and plagioclase of the diffraction peaks 3,$20 ; 4,04 ; 2,96 ; 2,51 \AA$. Quartz has a high crystallinity and accurately diagnosed by diffraction peaks 3,$34 ; 1,82 ; 1,54 ; 4,25 ; 2,45 ; 2,28 ; 2,12 \AA$. group minerals chlorite and kaolinite by peaks 7,$12 ; 3,53 ; 14,5 ; 4,68,2,33 \AA$.

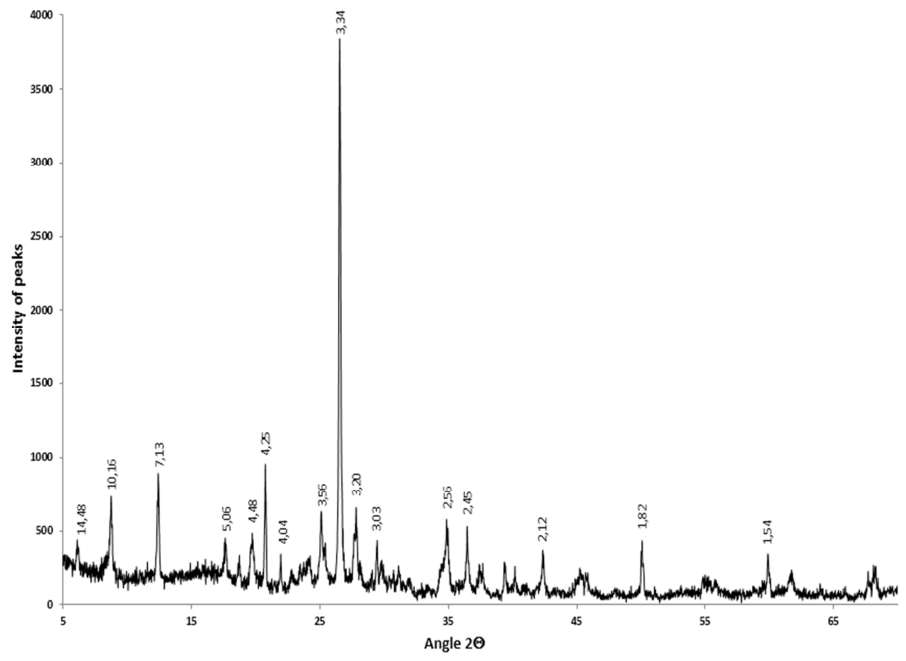

Fig.1. Radiographs screenings from coal dumps of Eastern Donbass.

Chemical and mineralogical composition determines the fluidity of screenings. At temperatures of $1000-1050^{\circ} \mathrm{C}$ they begin to sinter, and under the temperature of $1100^{\circ} \mathrm{C}$ pass into pyroplastic state (Fig. 2,3). Fusible screening is a favorable factor. It allows to obtain products with the required degree of sintering and hence the physical and mechanical properties at relatively low firing temperatures, to accelerate the process and reduce production costs. 


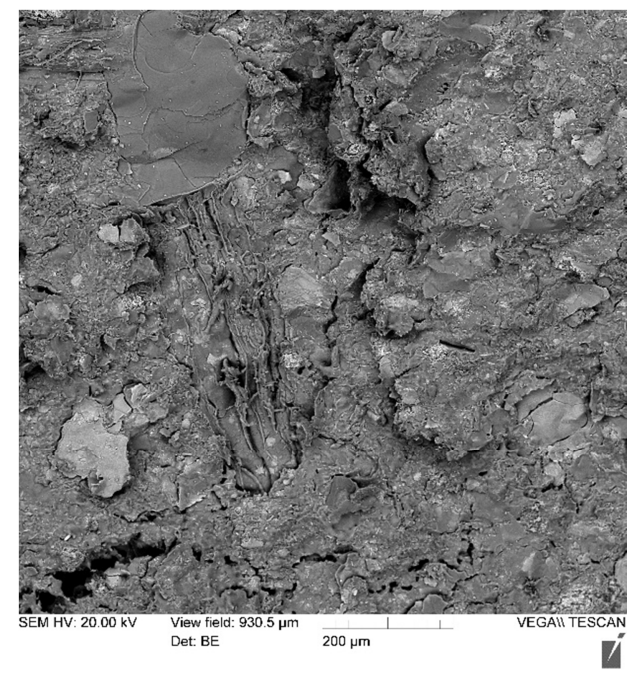

Fig. 2. Microscopic picture screenings pieces baked at $1000^{\circ} \mathrm{C}$.

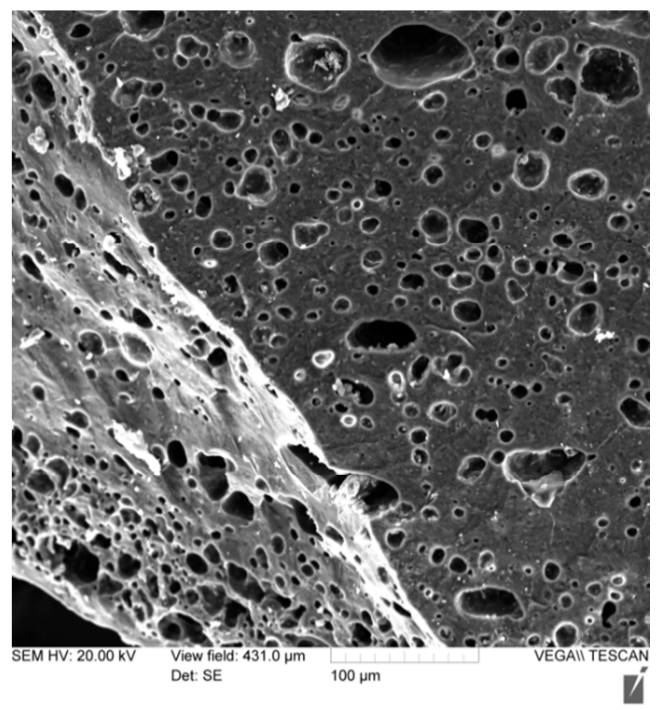

Fig. 3. A microscopic picture screenings pieces fired at $1100^{\circ} \mathrm{C}$.

The mineralogical composition and the structural features screenings cause before fired specific ceramic properties. Plasticity Number even during grinding to $0-0,16 \mathrm{~mm}$ fraction is less than 6.5 units, which is not sufficient for the formation of products by extrusion. They are insensitive to the drying and have a low binding capacity - the flexural strength of the dried sample less than $1 \mathrm{MPa}$. However burnt samples based on them have sufficiently high strength. Thus, strength of fired samples is very dependent on the degree of the feedstock grinding and the firing temperature (Fig. 4). As it is seen from the results, firing at the temperature of $950-1050^{\circ} \mathrm{C}$ and grinding to screenings fractions $0-0,315-0-0,63$ $\mathrm{mm}$ provides a tensile strength greater than $10 \mathrm{MPa}$ products when voidage is $50 \%$. 


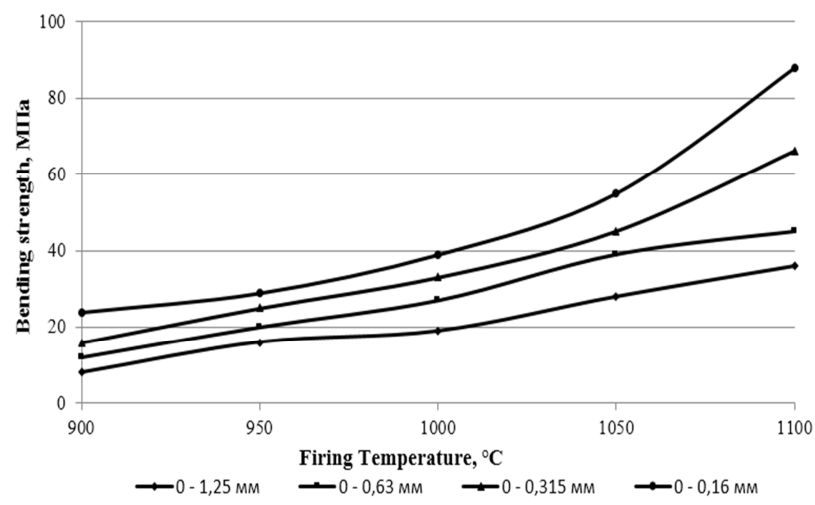

Fig. 4. The dependence of the compressive strength of the samples fired firing temperature.

Entering of coal slurries can improve plasticity and connectivity of raw mass. However, the coal content in the sludge of about $35 \%$ and provided with the amount of fuel injected from the raw materials which should not exceed $80 \%$ and the coal slurry should not exceed $22 \%$. With this amount, mass plasticity reaches $7-8$ units, which is insufficient for extrusion of molding products. An integrated technological approach predetermines the evaluation of coal slurries as a combined additive. In addition to improve the molding properties, they act as burnable fuel additives to reduce the density of the ceramic crock and considerably reduce the consumption of gas on firing. The cost of heat calories generated in them in 1520 times lower compared to the pure gas and coal. If the cost of clean coal and natural gas is 7000-9000 rubles per ton, the price of coal slurry 200-400 rubles per ton.

Combustion of coal particles during the firing facilitates forms of porous structure of ceramic material, which contributes to a significant reduction in product density and thermal conductivity. However, it reduces the strength of products. Therefore, determination of the optimum number of input sludge process is not a simple task. The figure 5 shows the dependence of the compressive strength of the samples at the content of coal slurries of $22 \%$ of the calcining temperature during grinding screenings to fractions 0 0,63 and $0-0,315 \mathrm{~mm}$.

As it can be seen, when the content of the coal slurry in the feed mixture in an amount of $22 \%$ of the strength of the samples is quite sufficient for obtaining large-size highperformance ceramic stones with 50\% voidage and trademark of M100 and higher strength. The firing temperature should be 950-1050 ${ }^{\circ} \mathrm{C}$ while depending on the required strength. The average density of the shard is $1480-1620 \mathrm{~kg} / \mathrm{m} 3$. Given voidage of $50 \%$ average density products will be $750-800 \mathrm{~kg} / \mathrm{m} 3$. It is possible to increase the emptiness of products, since there is a margin of safety of the ceramic material. Produced currently stones large size ceramic with vertical cavities have voidage to $60 \%$, and with a horizontal arrangement of voids to $70 \%$, but have substantially lower strength. 


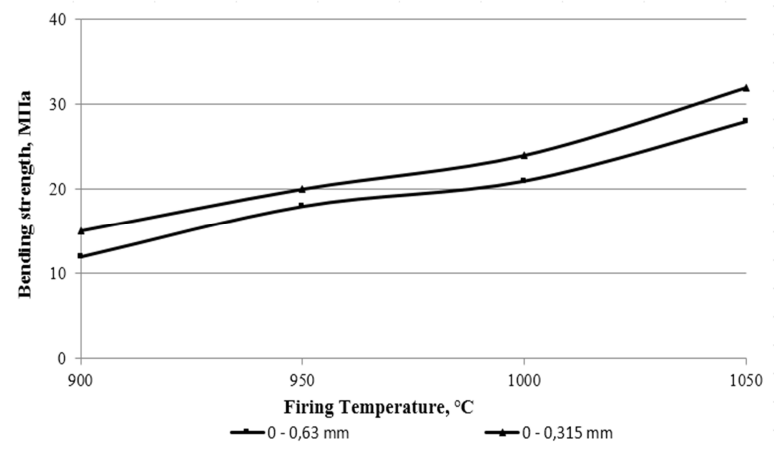

Fig. 5. The dependence of the compressive strength of the samples fired at the temperature of coal slurry content $-22 \%$.

To increase the plasticity of ceramic masses based on screenings, increase their structural strength and improve formability, it is recommended to add siliceous clay into mass according to the results of our experiments. These rocks are widely distributed in the south of Russia. Their main feature is its composition such as mineral groups, in an amount of $50-60 \%$ and silica opal as residues of diatoms, sponge spicules, and radiolarian in the amount of about $30 \%$. They are characterized by high ductility (22-28 Units) and good formability. Ceramic material which is based on them is different in lower average density $(1550-1650 \mathrm{~kg} / \mathrm{m} 3)$ due to the microporous structure of opaline silica. For example, in the Table 2 the chemical composition of siliceous clay which was used in our experiments is depicted.

Table 2. Averaged chemical composition of siliceous clay.

\begin{tabular}{|c|c|c|c|c|c|c|c|c|}
\hline $\mathbf{P P P}$ & $\mathbf{S i O}_{\mathbf{2}}$ & $\mathbf{A I}_{\mathbf{2}} \mathbf{O}_{\mathbf{3}}$ & $\mathbf{F e}_{\mathbf{2}} \mathbf{O}_{\mathbf{3}}$ & $\mathbf{C a O}$ & $\mathbf{M g O}$ & $\mathbf{S O}_{\mathbf{3}}$ & $\mathbf{K}_{\mathbf{2}} \mathbf{O}$ & $\mathbf{N a}_{\mathbf{2}} \mathbf{O}$ \\
\hline $6-7$ & $68-70$ & $13-15$ & $4-5$ & $1-2$ & $0,5-1$ & $0,1-0,4$ & $1,5-2,5$ & $0,4-0,6$ \\
\hline
\end{tabular}

Results of experimental research, including semi-works conditions showed that the introduction in a ceramic mass to $10 \%$ siliceous clays, provides the necessary ductility and formability, while the strength of fired samples increases by $15-20 \%$ without an increase in average density, it means that to achieve the desired strength of the product with the introduction of siliceous clays, it can be burnt to $20-30^{\circ} \mathrm{C}$.

The results of our research have allowed to develop, in our opinion, an optimum technological scheme of high-performance production of large-size ceramic blocks, which are based on products of processing coal dumps (screenings and coal slurry) to form semirigid articles by extrusion, drying products in a tunnel dryer on kiln trolleys at the following component: screenings - $65-70 \%$; coal slurries - and $20-25 \%$ siliceous clay - $10 \%$. The Figure 6 shows the scheme without transport and auxiliary equipment.

The basic operation in preparing raw meal is grinding of screenings to fractional composition of $0-0,315$ to $0-0,63 \mathrm{~mm}$. The best way is to use a hammer mill and either shaft, pendulum, ball mill or fine grinding mills. Coal slurries do not need grinding, as they are already in a finely dispersed condition. The main task is to mix thoroughly all components and control raw humidity, which is $14-16 \%$ for this raw material and its molding method. To do this, two mixers should be provided. The Molding process is carried out at a press extruder. The extruder, production of the republic of Belarus CM$506 \mathrm{M}$ or Western equipment manufacturers, may be used. The presence of finely divided coal has particularly beneficial effect for the molding at elevated pressures, since coal is a kind of "lubricant". The main object of the technology is the optimization of the molding parameters (molding temperature, die pressure press beam output speed, vacuum level, 
steam temperature etc.) to produce products with sufficient strength for the cages at the kiln cars.

The absence of such operations as the installation and removal rates of products with drying trolleys considerably simplifies the technological production scheme. Moreover, for the raw mass based on screenings at sufficient length of the furnace (150 meters or more), as a separate drying operation may be absent. During firing, the main task is to ensure the complete combustion of coal component, and the maintenance of the required firing mode. In this case, firing process can be performed completely only with coal via the following scheme: $80 \%$ fuel - in products themselves, $20 \%$ - coal, is fed through special burners. It should be mentioned that the presence of fuel within the product promotes roastin, $g$ both of the product itself and the whole cage. Entering of sawdust, straw flour, sunflower husks or rice hulls into the mass in the amount of $1-2 \%$, improves calcination conditions due to earlier ignition of coal combustion and expansion of zones, since data organic materials ignite at lower temperatures than coal $\left(450-600^{\circ} \mathrm{C}\right)$. In this case, due to the thermal decomposition of wood (pyrolysis) allocated combustible pyrolysis gases begin to emiss actively, what also contributes to the expansion of burning zone.

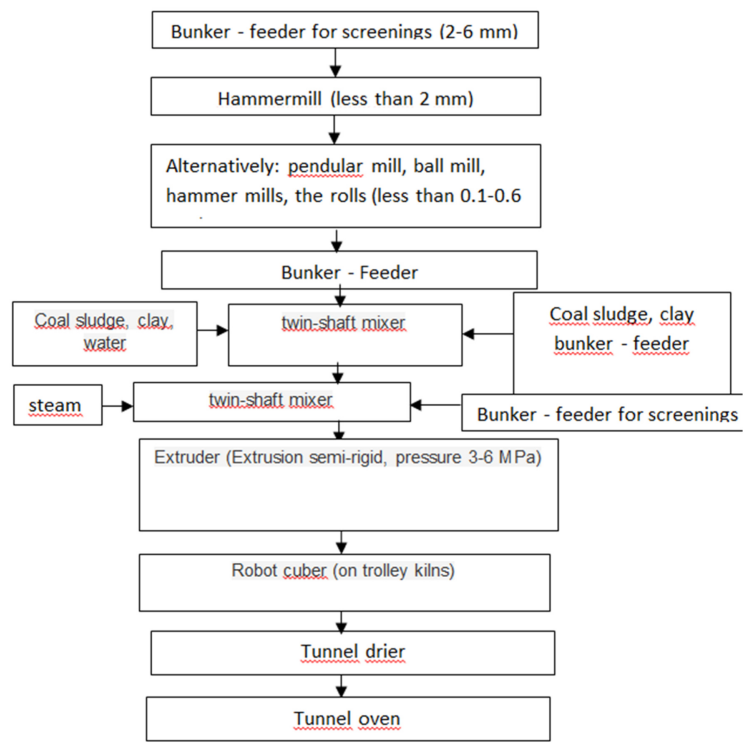

Fig. 6. Technological scheme of clay tiles production on the basis of screenings and coal slurry.

From all represented equipment in the scheme, the biggest part of it is domestic. An exception is an extruder for molding articles and robots for placing and removal rate of products with a kiln car. Extruders are produced in many European countries, for example in Turkey. The optimal solution for "price - quality" extruders produced by the Spanish company "Verdes". The most commonly used in the ceramics industry robots produced in Japanese company «Fanuc», which proved to be of good quality. 


\section{Conclusions}

The results of the research allowed to choose raw materials and to develop the technological scheme of high-performance ceramic stones production with a minimum cost. Low production cost will be achieved at the expense of:

1. practically free raw materials;

2. simplified flowsheet preparation of raw mix;

3. forming articles rigid extrusion method;

4. rapid drying products on trolleys in the tunnel kiln dryer;

5. the minimum cost of baking products due to the use of coal slurry;

6. ?highly automated production with

7. minimal use of manual labor.

Implementation of the results in practice will create a highly profitable production and to make the Rostov region a major manufacturer of ceramic wall.

\section{References:}

1. F. Pacheco-Torgal, P.B. Lourenço, J.A. Labrincha, S. Kumar, P. Chindaprasirt, Desing, Properties and Durability, Copyright Elsevier Ltd: Eco-efficcient Masonry Bricks and blocks (2015)

2. G. H. M. J. Subashi De Silva, B. V. A. Perera, J. Build. Eng., 18, 252-259

3. A.A. Semenov, Buil. Mater., № 8, 49-5 (2018)

4. V. Kotlyar, Kh. Yavruyan, E. Gaishun, Y. Teryokhina, WASTE'2018, 22-24 (2018)

5. A.A. Semenov, Buil. Mater., № 4, 4-8 (2017)

6. Kh.S. Yavruyan1, V.D. Kotlyar, E.S. Gaishun, Mater. Techn. Const. Arch. Mat. Sci. For. Sub., 931, 532-536 (2018)

7. G.I. Storozhenko, A.Y. Stolboushkin, A.I. Ivnov, Build. Mate., № 8 (2015)

8. V.D. Kotlyar, A.V. Ystinov, Y.V. Terekhina, A.V. Kotlyar, Tech. Techn. Silic., 4, 8-15 (2014)

9. V.D. Kotlyar, Y.V. Terekhin, A.V. Kotlyar, Build. Mate., № 4 (2014)

10. A.Yu. Stolboushkin, A.I. Ivanov, O.A. Fomina, ICIE, 1496 - 1502 (2016)

11. A.V. Kotlyar, Vestnik TSAU, № 2, 164-175 (2016)

12. Kh.S. Yavruyan, V.D. Kotlyar, E.S. Gaishun, Mat. Tech. Const. Arc.. Mate. Sci. For. Sub., 931, 532-536 pp.

13. Kh. Yavruyan, E. Gaishun, Y. Teryokhina, V. Kotlyar, MATEC Web Conf., 196 (2018)

14. A.Y. Stolboushkin, G.I. Storozhenko: Build. Mater., 4, 43-46 (2011)

15. G.S. Golovin, A.S. Maloletnev: Business Directory: Complex processing of coal and improving the efficiency of their use (2007)

16. V.D. Kotlyar, Kh.S. Yabruyan, Build. Mater., 4, 38-41 (2017) 